\title{
Identity Formation in Adolescence: Change or Stability?
}

\author{
Theo A. Klimstra • William W. Hale III • \\ Quinten A. W. Raaijmakers · Susan J. T. Branje • \\ Wim H. J. Meeus
}

Received: 26 November 2008/ Accepted: 12 February 2009/Published online: 27 February 2009

(C) The Author(s) 2009. This article is published with open access at Springerlink.com

\begin{abstract}
The aim of this five-wave longitudinal study of 923 early to middle adolescents ( $50.7 \%$ boys; $49.3 \%$ girls) and 390 middle to late adolescents ( $43.3 \%$ boys and $56.7 \%$ girls) is to provide a comprehensive view on change and stability in identity formation from ages 12 to 20 . Several types of change and stability (i.e., mean-level change, rankorder stability, and profile similarity) were assessed for three dimensions of identity formation (i.e., commitment, in-depth exploration, and reconsideration), using adolescent self-report questionnaires. Results revealed changes in identity dimensions towards maturity, indicated by a decreasing tendency for reconsideration, increasingly more in-depth exploration, and increasingly more stable identity dimension profiles. Mean levels of commitment remained stable, and rank-order stability of commitment, in-depth exploration, and reconsideration did not change with age. Overall, girls were more mature with regard to identity formation in early adolescence, but boys had caught up with them by late adolescence. Taken together, our findings indicate that adolescent identity formation is guided by progressive changes in the way adolescents deal with commitments, rather than by changes in the commitments themselves.
\end{abstract}

Keywords Identity formation - Longitudinal . Adolescence

T. A. Klimstra $(\square)$. W. W. Hale III .

Q. A. W. Raaijmakers - S. J. T. Branje - W. H. J. Meeus Research Centre Adolescent Development, Utrecht University, P.O. Box 80.140, 3508 TC Utrecht, The Netherlands

e-mail: t.a.klimstra@uu.nl

\section{Introduction}

Erikson proposed that identity formation is the key developmental task of adolescence (Erikson 1972). Therefore, identity formation has been hypothesized to involve "changes in identity that can be characterized as progressive developmental shifts" (Waterman 1982; p. 355, italics added). However, there is a lack of longitudinal studies investigating the dynamics of identity formation across the entire period of adolescence. Moreover, there has been a debate on whether identity formation is better characterized by change or by stability (Van Hoof 1999; Waterman 1999). The current study aims to provide a comprehensive view on adolescent identity formation by examining various aspect of change and stability, using five-annual-wave longitudinal data on early to middle and middle to late adolescent boys and girls.

The most commonly used conceptualization of Erikson's identity theory is Marcia's identity status paradigm (Marcia 1966). In this paradigm, the focus is on two dimensions central to Erikson's work on identity: exploration of developmental alternatives in various salient identity-defining domains (referred to as "crisis" in Erikson's work); and selection of alternatives as well as engaging in relevant activities towards the implementation of these choices (commitment). Marcia proposed that, based on the amounts of exploration and commitment, an adolescent's identity can be classified into either one of four distinguishable identity statuses: diffusion (low in exploration and low on commitment), foreclosure (little exploration, but strong commitments), moratorium (high on exploration, but no stable commitments as yet), and achievement (high on commitment after a period of extensive exploration). There is consensus that diffusion should be considered as the least adaptive status, 
foreclosure and moratorium are two intermediate statuses, and achievement is the most adaptive status (Waterman 1999).

Studies on Identity Formation: From a Status Approach Towards a Dimensional Approach

Marcia's identity status paradigm (Marcia 1966), originally developed as an attempt to classify an adolescent's identity status at a certain point in time (Marcia 2007), has inspired hundreds of empirical investigations of identity formation (for reviews, see for example: Meeus 1996; Kroger 2007). Following Erikson's assumption that identity formation involves a developmental process (Erikson 1972, 1974), a limited number of these studies has used a longitudinal approach. These studies have assessed changes in identity formation in either one of two ways: (1) by focusing on changes in identity status, or (2) by focusing on changes in separate identity dimensions. We will first discuss studies on changes in identity status, and then discuss the merits of studying longitudinal changes in identity formation with separate measures of commitment and exploration.

In a review of studies examining identity status change, Waterman $(1982,1999)$ concluded that the basic hypothesis underlying Erikson's work on identity ("movement from adolescence to adulthood involves changes in identity that can be characterized as progressive developmental shifts", p. 355, italics added), has received support in empirical studies. This hypothesis is also referred to as the fundamental developmental hypothesis of identity formation. The progressive developmental shifts Waterman (1982) refers to are changes from less adaptive identity statuses (e.g., diffusion) towards the most adaptive status (i.e., achievement). However, not everyone agrees with Waterman's notion of progressive developmental shifts. Based on the same studies where Waterman (1999) noted progressive changes, Van Hoof (1999) concluded that identity status studies have more often found stability than change. Yet, she did note that if change does occur it is more likely to be progressive than regressive. The contradiction between the conclusions of Waterman and Van Hoof is caused by the fact that Waterman emphasized that progressive change outweighs regressive change, whereas Van Hoof stressed that stability occurred more often than progressive changes did. Both positions received support in a recent meta-analysis by Kroger (2007), as she found equal probabilities of stability and progressive developmental changes in identity formation, while progressive change was much more common than regressive change. In sum, previous studies on identity status change indicate that identity formation in adolescence is either characterized by stability, or by progressive change. Apart from a debate concerning the amount of change in identity formation, there is also disagreement on the timing of changes in identity formation in adolescence. Several overview studies (e.g., Marcia 1980; Waterman 1982, 1993) concluded that changes in identity formation were most likely to occur in late adolescence, whereas Meeus et al. (1999) found that changes were just as common in early and middle adolescence, as in late adolescence.

Thus, longitudinal studies on changes in identity status have not led to consensus on either the direction or the timing of changes with regard to identity formation. This could be caused by the fact that studies on identity status change merely provide a rough estimate of the overall direction of identity formation and are not informative on longitudinal changes in the underlying dimensions of commitment and exploration (Matteson 1977). Identity status changes only occur when the amount of change in the underlying dimensions passes a certain threshold, whereas an approach with a focus on separate dimensions of commitment and exploration is also sensitive to smaller changes in identity formation (Meeus 1996). For that reason, studies focusing on separate identity dimensions could shed new light on the change versus stability debate (van Hoof 1999; Waterman 1999) that has mainly been related to the identity statuses until now. Therefore, the current study aims to contribute to the change versus stability debate by examining the developmental course of the dimensions underlying the statuses.

Several identity models with a focus on separate dimensions of exploration and commitment have been introduced since the late 1990s (Balistreri et al. 1995; Luyckx et al. 2006b; Meeus 1996). In the current study, a recently developed three-dimension model will be applied to assess stability and change in identity formation. We will now discuss this three-dimension model, and then review the few longitudinal studies that have followed a dimensional approach to identity formation.

\section{A Three-Dimension Model of Identity Formation}

In 2001, Meeus designed a new measure to assess identity formation: the Utrecht-Management of Identity Commitments Scale (U-MICS; Crocetti et al. 2008b). U-MICS is partly based on a previous measure, the Utrecht-Groningen Identity Development Scale (U-GIDS; Meeus 1996), as it contains commitment and in-depth exploration scales. However, a relatively new exploration scale was added: reconsideration.

The definition of commitment in U-MICS (Crocetti et al. 2008b) is similar to the original definition by Marcia (1966), and refers to being committed to one's choice of identity. However, whereas Marcia assessed one type of exploration, two types of exploration are distinguished in U-MICS: in-depth exploration and reconsideration of 
commitment. In-depth exploration represents the extent to which adolescents explore current commitments actively, reflect on their choices, search for additional information about these choices, and discuss their current commitments with relevant others (i.e., friends or family). It refers to adolescents exploring the merits of their current commitments, without questioning the commitments themselves. Reconsideration of commitment refers to adolescents comparing their present commitments with possible alternative commitments. When reconsideration occurs, it has a short-term detrimental effect on adolescents, as it reflects uncertainty about commitments and is therefore positively related to problem behaviors such as depression and delinquency (Crocetti et al. 2008b). However, when the developmental context of an individual changes, it can be necessary to re-evaluate or even replace old commitments. Thus, the long-term effects may, in fact, be positive since adapting one's commitments can be necessary when current commitments are no longer suitable in a new context.

The three dimensions of U-MICS cover three important aspects from the broader Eriksonian perspective on identity formation and Marcia's elaboration on that perspective. First, reconsideration involves comparisons of present commitments with possible alternatives, and the possible replacement of present commitments as a result of these comparisons. Thereby, reconsideration captures an important facet of identity formation as described by Erikson (1972), who stated that "in puberty and adolescence all samenesses and continuities relied on earlier are more or less questioned again" (pp. 252-253). Second, the threefold conceptualisation of identity formation involves a double evaluation process of present commitments, comparable to a recent addition to Marcia's identity status paradigm: the dual-cycle model proposed by Luyckx et al. (2006a). They distinguish between a commitment formation cycle, referring to the formation of stable commitments, and a commitment evaluation cycle, capturing the process of evaluating and actively thinking about commitments. Since reconsideration refers to comparing present commitments with alternative ones, decreases in reconsideration signify increases in certainty about current commitments. Therefore, reconsideration partly fits into the commitment formation cycle. In-depth exploration fits into the commitment evaluation cycle because it indicates an adolescent's reflection on his/her present commitments, without questioning the commitments themselves.

Third, although Meeus and colleagues (Crocetti et al. 2008b) distinguish two instead of one exploration dimension (e.g., in-depth exploration and reconsideration), they were able to replicate the four identity statuses Marcia (1966) originally found (Crocetti et al. 2008a). However, while Marcia only found one moratorium status, Crocetti et al. (2008a) found two distinctive moratoria-statuses (i.e., moratorium and searching moratorium). Even so, the findings of Crocetti et al. (2008a) demonstrate the convergent validity of the three-dimension model.

In this study, the three U-MICS dimensions (Crocetti et al. 2008b) will be used to assess identity formation through adolescence. Similar to other identity measures like the Identity Status Interview (ISI; Marcia 1966), the Extended version of the Objective Measure of Ego Identity Status (EOM-EIS; e.g., Bennion and Adams 1986), and the Ego Identity Process Questionnaire (EIPQ; Balistreri et al. 1995), U-MICS allows identity dimensions to be assessed in the ideological domain (i.e., education) and the interpersonal domain (i.e., friendships). However, as the main aim of the current study is to examine change and stability in identity formation in general and not to assess differences between identity domains, identity dimensions will be assessed at a global level. Crocetti et al. (2008b) showed that U-MICS is well-suited for measuring global identity dimensions, as they have demonstrated that collapsing ideological and interpersonal dimensions into global identity dimensions did not affect the factor structure or the reliability of U-MICS.

\section{Three Types of Change in Identity Dimensions}

Change can be operationalized in several ways. In the related field of adolescent personality development, a case has been made for the assessment of various distinct types of change in one research design to obtain a comprehensive perspective on development. These types of change are: changes in mean levels, changes in the rank-order of individuals, and changes in profiles consisting of various traits (e.g., Block and Robins 1993). All three components add a unique piece of information, and together they provide a comprehensive perspective on development. Several studies in the field of personality have followed such an approach (e.g., De Fruyt et al. 2006; Roberts et al. 2001; Robins et al. 2001), yet all three change components have not been used together in one research design for the examination of identity formation. Two components have been examined in previous studies on change and stability in identity commitment and exploration: mean-level change and rank-order stability. The third, profile similarity, is new to the field of identity formation. We will now discuss these three indices of change and stability, and explain how they complement one another.

\section{Mean-Level Change}

The most obvious way to examine progressive changes in identity dimensions is to assess whether mean scores of a population on commitment and exploration change in a favourable direction. Only three longitudinal studies have 
followed such an approach. In these studies, Meeus et al. (1999) found increases of commitment and in-depth exploration during adolescence. Luyckx et al. (2006a) and Luyckx et al. (2008) also found an increase in in-depth exploration. Luyckx et al. (2006a) further demonstrated increases in exploration of alternative commitments (they label this dimension as exploration in breadth, but it is conceptually quite similar to the reconsideration dimension assessed with U-MICS), but Luyckx et al. (2008) showed that this increase was followed by a decrease. Luyckx and colleagues distinguish two commitment dimensions: commitment making and identification with commitment. For identification with commitment, the dimension that is most similar to the commitment dimensions by Marcia (1966) and Crocetti et al. (2008b), decreases over time were found. Thus, there is agreement on longitudinal increases for in-depth exploration, but findings concerning commitment are inconsistent and call for more longitudinal research. Findings for exploration in breadth (i.e., conceptualized as reconsideration in the present study) suggest that increases are followed by decreases. This is in line with Marcia's (1966) reasoning that the most advanced identity status (i.e., achievement) represents strong commitments formed after a period of exploration in breadth, and suggests that adolescents indeed seem to move towards an achieved identity as they grow older (e.g., Waterman 1982, 1999). Based on the above mentioned studies, we expect adolescent identity formation in the three-dimension model used in the current study (Crocetti et al. 2008b) to be characterized by increases for in-depth exploration and a decreasing tendency to reconsider commitment. Furthermore, this study might clear up the inconsistent pattern of development of commitment found in previous studies.

The aforementioned longitudinal studies did not add to the earlier mentioned debate on the timing of identity formation in adolescence, as they did not compare the amount of change in identity dimensions in early to middle and middle to late adolescence. The design of the current study allows for a longitudinal exploration of where in adolescence changes are most common.

\section{Rank-Order Stability}

Indices of mean-level change are only informative on the average direction and amount of change in a sample. Rankorder stability, on the other hand, indicates whether the rank-order of individuals on a certain trait is maintained over time. Mean-levels of an identity dimension could change, but these changes only represent normative development reflecting universal maturation processes if they are accompanied by high levels of rank-order stability (e.g., Roberts and DelVecchio 2000). Thus, indices of rank-order stability are needed alongside measures of mean-level change to indicate whether the observed changes apply to a majority of individuals in a sample. In addition, changes in rank-order stability itself can indicate when in adolescence inter-individual differences in several dimensions of identity formation start to become more settled.

There are three studies examining rank-order stability of identity dimensions. Over a six-month period, Luyckx et al. (2008) found relatively high rank-order stability for identity dimensions and both Luyckx et al. $(2006 a, c)$ reported similar results over a one-year and a two-year period (correlations ranging from .40 to .77). All studies indicated that there was a substantial amount of within-group stability. Since previous studies have shown that rank-order stability of identity dimensions is high over a period up to 2 years, we expect at least medium rank-order stability (i.e., higher than .30; Cohen 1988) for identity dimensions over a four-year period.

To determine in what part of adolescence inter-individual differences in change are most common, and thus to investigate when inter-individual differences in identity dimensions start to become more settled, indices of rankorder stability in various periods of adolescence have to be compared. The current study is the first that will explore differences in rank-order stability in early, middle and late adolescence.

\section{Profile Similarity}

A third aspect of change and stability, profile similarity, has so far not been assessed in the field of identity formation. The technique has been applied in the related field of adolescent personality research (e.g., Block 1971; Ozer and Gjerde 1989; Roberts et al. 2001). Profile similarity provides information on the stability of a constellation of traits over time within a person, and is therefore, unlike rank-order stability and mean-level change, not informative on changes in individual identity dimensions. Because profile similarity indicates to what extent a person's configuration of identity dimensions changes over time, it is also different from other change indices and is not indicative of changes at the sample level. Profile similarity is usually calculated with $q$-correlations. Like Pearson correlations, $q$-correlations range from -1 to 1 . The higher the $q$-correlation, the more stable a constellation of identity dimensions within a person is (e.g., Ozer and Gjerde 1989; Roberts et al. 2001). In the current study, profile similarity is defined as intra-individual change in the rank-ordering of three identity dimensions (commitment, in-depth exploration, and reconsideration). High levels of profile similarity would indicate that an adolescent has a steady identity profile, whereas low levels of profile similarity would indicate profound fluctuations in the shape of an identity profile. Thus, the amount of profile similarity is to some 
extent informative on the stability of identity structures of adolescents.

As profile similarity has, so far, not been used in the field of identity formation research, our examination of this change index will be exploratory in nature. This examination may provide additional information on whether identity formation mainly takes place in late adolescence, as advocated by Marcia (1980) and Waterman (1982, 1993), or throughout the entire adolescent period, as Meeus (1996) presumes.

\section{Gender Differences}

Debates relating to gender differences in identity formation can be traced back to Erikson (1974) who claimed that women would have to keep their identities open, to adjust to the peculiarities of the men they would eventually meet and to the children they would raise. Nowadays, such a statement should be considered as outdated in Western countries, since both men and women pursue occupational careers and childrearing has become much more of a mutual process with men and women sharing such tasks. Considering these societal changes, gender differences in identity formation might have disappeared as well. In fact, several researchers (e.g., Kroger 1997; Waterman 1982, 1993, 1999) concluded in overviews that there were no general differences in the prevalence of identity statuses among men and women, a conclusion that has been reconfirmed in an extensive empirical study by Meeus et al. (1999). Notwithstanding a lack of evidence for gender differences in the prevalence of identity statuses, it is still possible that there are gender differences in the identity dimensions underlying the statuses (i.e., exploration and commitment). Recent longitudinal studies on identity dimensions have mainly been conducted by Luyckx and colleagues (Luyckx et al. 2006a, 2008). They employed samples predominantly comprised of females, and were therefore unable to test for gender differences. Thus, gender differences in longitudinal changes and stability of identity dimensions of exploration and commitment yet need to be investigated. The current study will set out to explore such gender differences in all three mentioned aspects of change (i.e., mean-level change, rank-order stability, and profile similarity).

\section{Aims of the Current Study}

The aim of this study is to examine how adolescent identity formation is best described. We expect identity formation to be described by mean-level increases in in-depth exploration and a decreasing tendency for reconsideration. This study also seeks to clarify the inconsistent pattern of development of commitment found in previous studies. Two other research questions will be examined in an explorative manner. First, we will use indices of rank-order stability to determine where in adolescence inter-individual differences in three separate identity dimensions start to become more settled. Second, we will assess profile similarity of identity dimensions to find out where in adolescence identity profiles including three identity dimensions start to become more stable. In addition, gender differences in all three aspects of change and stability will be explored.

\section{Method}

\section{Participants}

Data for this study were collected as part of a five-wave longitudinal research project on CONflict And Management Of RElationships (CONAMORE; Meeus et al. 2006), with a one-year interval between each of the waves. The longitudinal sample consisted of 1,313 participants divided into an early to middle adolescent cohort $(n=923$; $70.3 \%$ ), who were 12.4 years of age on average $(\mathrm{SD}=.59)$, and a middle to late adolescent cohort $(n=390 ; 29.7 \%)$ with an average age of 16.7 years $(\mathrm{SD}=.80)$ during the first wave of measurement. The early to middle adolescent cohort consisted of 468 boys $(50.7 \%)$ and 455 girls $(49.3 \%)$, the middle to late adolescent cohort consisted of 169 boys (43.3\%) and 221 girls $(56.7 \%)$. Because both age groups were assessed during five measurement waves, a total age range from 12 to 20 years was available. Participating adolescents were recruited from various randomly selected junior high and high schools in the province of Utrecht, The Netherlands. As the composition of the population of Utrecht closely mirrors that of the Dutch population as a whole (Statistics Netherlands 2003), our sample was representative for the general Dutch adolescent population.

Sample attrition was $1.2 \%$ across waves: in waves 1,2 , 3 , 4, and 5 the number of participants was 1,313, 1,313, 1,293, 1,292 and 1,275, respectively. Across waves $2.6 \%$ of the data was missing. Missing values were estimated in SPSS, using the EM-procedure. Little's Missing Completely At Random Test (Little 1988) revealed a normed $\chi^{2}$ $\left(\chi^{2} / d f\right)$ of 1.78 , which according to guidelines by Bollen (1989) indicates a good fit between sample scores with and without imputation.

Procedure

Participants and their parents received an invitation letter, describing the research project and goals, and explaining 
the possibility to decline from participation. More than $99 \%$ of the approached high school students decided to participate. All participants signed the informed consent form. The questionnaires were completed at the participants' own high school, during annual assessments. Confidentiality of responses was guaranteed. Verbal and written instructions were offered. The adolescents received $€ 10$ (approximately US $\$ 15$ ) as a reward for every wave they participated in.

\section{Measures}

\section{Identity Formation}

Identity formation was assessed with the Utrecht-Management of Identity Commitments Scale (U-MICS), a selfreport measure designed by Meeus (Crocetti et al. 2008b) based on the U-GIDS (Meeus 1996). With this instrument, 5-point Likert-scale items, with a response format ranging from 1 (completely untrue) to 5 (completely true), are used to assess three identity dimensions: commitment (five items), in-depth exploration (five items), and reconsideration (three items). The same items can be filled out to assess identity dimensions in different domains. In the current study, we focused on one ideological domain (i.e., education) and one interpersonal domain (i.e., friendships) that play an important role in the lives of all adolescents.

Because we assessed two domains with 13 items each, the total number of items of U-MICS was 26 in the current study. Sample items are: "My education/best friend gives me certainty in life" (ideological/interpersonal commitment), "I think a lot about my education/best friend" (ideological/interpersonal in-depth exploration), "I often think it would be better to try and find different education/a different best friend" (ideological/interpersonal reconsideration). Although U-MICS allows for identity dimensions to be measured in different content domains, we focused on identity dimensions at a global level. For this purpose we followed the scale construction procedure described by Crocetti et al. (2008b). A detailed description of the validity of U-MICS is provided by Crocetti et al. (2008a, b). Reliability of U-MICS was high across waves for commitment (Cronbach's alphas .91-.95), in-depth exploration (Cronbach's alphas .84-.92), and reconsideration (Cronbach's alphas .92-.94).

\section{Results}

Mean-Level Change in Identity Dimensions

Mean-level change in identity dimensions was estimated with a multivariate Latent Growth Curve Model (LGCM;
Duncan et al. 1999) in Mplus (Muthén and Muthén 2007). LGCM provides mean levels (i.e., intercepts) and mean change rates (i.e., slopes), which are based on individual growth trajectories of all participants. Maximum Likely Robust estimation (MLR) was used, as MLR gives the most accurate estimate of chi-squares when the distribution of scores deviates from a normal distribution (Satorra and Bentler 1994), which turned out to be the case for scores on our identity formation measure.

We used a multigroup longitudinal design with four groups: early to middle adolescent boys and girls, and middle to late adolescent boys and girls. Because there was a one-wave overlap between the early to middle and middle to late adolescent cohorts, we were able to infer an accelerated perspective (e.g., Duncan et al. 1999) by placing the intercept on the one wave of overlap between these two age cohorts (i.e., slope factor loadings were $-4,-3,-2,-1$, and 0 for the five consecutive measurement occasions for early to middle adolescent boys and girls, and $0,1,2,3$, and 4 for middle to late adolescent boys and girls). The accelerated design required us to constrain the means and variances of intercepts in the two cohorts to be equal. Chisquare difference tests revealed that an accelerated approach was justified, since the fit of a model with means and variances of intercepts constrained to be equal, did not significantly differ from the fit of a model where means and variances of intercepts were freely estimated. Means and variances of slopes were allowed to vary between the two cohorts, enabling us to examine whether developmental patterns of identity dimensions were different in early to middle and middle to late adolescence.

To determine what shape of growth characterized our data best, we first ran univariate accelerated Latent Growth Curve Models for each of the three identity dimensions (i.e., commitment, in-depth exploration, and reconsideration). Different types of latent growth models were estimated, that is: no growth, linear growth, and quadratic growth. The best model was chosen by comparing chi-squares of different models, using the procedure proposed by Satorro and Bentler (2001). Model fit was further judged by assessing RMSEA's, CFI's, and TLI's. RMSEA's smaller than .08, and CFI's and TLI's larger than .95 indicate an adequate model fit (Hu and Bentler 1999), and relatively lower RMSEA's, and higher CFI's and TLI's indicate better fits when comparing models (Kline 1998). Our univariate models revealed that commitment and in-depth exploration were best characterized by linear growth, whereas reconsideration was best characterized by curvilinear growth.

Second, we ran a multivariate multigroup model including growth curves of commitment, in-depth exploration, and reconsideration. To improve model fit, intercepts and slopes were allowed to correlate within a certain identity dimension, as well as between dimensions. Observed means and 
Table 1 Descriptive statistics of identity dimensions in early to middle adolescence and middle to late adolescence

\begin{tabular}{|c|c|c|c|c|c|c|c|c|c|c|}
\hline & \multicolumn{5}{|c|}{ Early to middle adolescence } & \multicolumn{5}{|c|}{ Middle to late adolescence $M$ (SD) } \\
\hline & $\begin{array}{l}\mathrm{T} 1 \\
M(\mathrm{SD})\end{array}$ & $\begin{array}{l}\mathrm{T} 2 \\
M(\mathrm{SD})\end{array}$ & $\begin{array}{l}\mathrm{T} 3 \\
M(\mathrm{SD})\end{array}$ & $\begin{array}{l}\mathrm{T} 4 \\
M(\mathrm{SD})\end{array}$ & $\begin{array}{l}\mathrm{T} 5 \\
M(\mathrm{SD})\end{array}$ & $\begin{array}{l}\mathrm{T} 1 \\
M(\mathrm{SD})\end{array}$ & $\begin{array}{l}\mathrm{T} 2 \\
M(\mathrm{SD})\end{array}$ & $\begin{array}{l}\mathrm{T} 3 \\
M(\mathrm{SD})\end{array}$ & $\begin{array}{l}\mathrm{T} 4 \\
M(\mathrm{SD})\end{array}$ & $\begin{array}{l}\mathrm{T} 5 \\
M(\mathrm{SD})\end{array}$ \\
\hline \multicolumn{11}{|l|}{ Boys } \\
\hline Commitment & $3.69(.63)$ & $3.73(.62)$ & $3.76(.62)$ & $3.71(.64)$ & $3.74(.58)$ & $3.70(.60)$ & $3.70(.58)$ & $3.63(.57)$ & $3.66(.61)$ & $3.71(.53)$ \\
\hline In-depth exploration & $3.20(.69)$ & $3.20(.69)$ & $3.22(.70)$ & $3.18(.67)$ & $3.17(.63)$ & $3.26(.64)$ & $3.20(.57)$ & $3.28(.51)$ & $3.28(.58)$ & $3.31(.60)$ \\
\hline Reconsideration & $2.22(.93)$ & $2.22(.94)$ & $2.21(.94)$ & $2.08(.87)$ & $1.95(.78)$ & $2.00(.73)$ & $1.99(.66)$ & $2.17(.71)$ & $2.11(.72)$ & $1.84(.55)$ \\
\hline \multicolumn{11}{|l|}{ Girls } \\
\hline Commitment & $3.72(.60)$ & $3.75(.63)$ & $3.71(.59)$ & $3.76(.59)$ & $3.78(.55)$ & $3.60(.52)$ & $3.68(.54)$ & $3.64(.57)$ & $3.66(.56)$ & $3.73(.55)$ \\
\hline In-depth exploration & $3.28(.62)$ & $3.23(.69)$ & $3.28(.61)$ & $3.25(.59)$ & $3.27(.58)$ & $3.27(.53)$ & $3.34(.52)$ & $3.41(.49)$ & $3.37(.49)$ & 3.39 (.49) \\
\hline Reconsideration & $1.88(.73)$ & $1.83(.79)$ & $1.89(.78)$ & $1.77(.72)$ & $1.74(.64)$ & $1.82(.62)$ & $1.82(.66)$ & $1.92(.70)$ & $1.83(.62)$ & $1.77(.66)$ \\
\hline
\end{tabular}

Table 2 Growth factors for early to middle and middle to late adolescent boys and girls

\begin{tabular}{|c|c|c|c|c|c|c|c|c|}
\hline \multirow[t]{3}{*}{ Growth Factors } & \multicolumn{4}{|l|}{ Boys } & \multicolumn{4}{|l|}{ Girls } \\
\hline & \multicolumn{2}{|c|}{ Early to middle adolescence } & \multicolumn{2}{|c|}{ Middle to late adolescence } & \multicolumn{2}{|c|}{ Early to middle adolescence } & \multicolumn{2}{|c|}{ Middle to late adolescence } \\
\hline & Mean & $\sigma^{2}$ & Mean & $\sigma^{2}$ & Mean & $\sigma^{2}$ & Mean & $\sigma^{2}$ \\
\hline \multicolumn{9}{|l|}{ Intercepts } \\
\hline Commitment & $3.73 * * *, \mathrm{a}$ & $.23 * * *$ & $3.73 * * *, \mathrm{a}$ & $.23 * * *$ & $3.72 * * *, \mathrm{a}$ & $.21 * * *$ & $3.72 * * *, \mathrm{a}$ & $.21 * * *$ \\
\hline In-depth exploration & $3.19 * * *$ a & $.26 * * *$ & $3.19 * * *, \mathrm{a}$ & $.26 * * *$ & $3.27 * * *, \mathrm{~b}$ & $.20 * * *$ & $3.27 * * *, \mathrm{~b}$ & $.20 * * *$ \\
\hline Reconsideration & $1.96^{* * * a \mathrm{a}}$ & $.30 * * *$ & $1.96^{* * *, \mathrm{a}}$ & $.30 * * *$ & $1.78 * * *, \mathrm{~b}$ & $.29 * * *$ & $1.78 * * *, \mathrm{~b}$ & $.29 * * *$ \\
\hline \multicolumn{9}{|l|}{ Linear Slopes } \\
\hline Commitment & $.01^{\mathrm{a}}$ & $.02 * * *$ & $-.01^{\mathrm{a}}$ & $.01 * * *$ & $.00^{\mathrm{a}}$ & $.02 * * *$ & $.00^{\mathrm{a}}$ & $.02 * * *$ \\
\hline In-depth exploration & $.01^{\mathrm{a}}$ & $.02 * * *$ & $.03^{*, \mathrm{a}, \mathrm{b}}$ & $.01 * * *$ & $.00^{\mathrm{a}}$ & $.02 * * *$ & $.04 * * *, \mathrm{~b}$ & $.01 * * *$ \\
\hline Reconsideration & $-.16^{* * *, \mathrm{a}}$ & .07 & $.14 * * *, \mathrm{~b}$ & .08 & $-.04^{\mathrm{c}}$ & $.09 * *$ & $.06^{\mathrm{b}}$ & $.15^{* * * *}$ \\
\hline \multicolumn{9}{|l|}{ Quadratic Slopes } \\
\hline Reconsideration & $-.02 * * *, \mathrm{a}$ & $.01 * *$ & $-.04 * * *, \mathrm{a}$ & .01 & $.00^{\mathrm{b}}$ & $.00 * *$ & $-.01^{\mathrm{a}, \mathrm{b}}$ & $.01 * * *$ \\
\hline
\end{tabular}

Note: Different superscripts within a line represent significant differences between groups $(p<.05)$. To infer an accelerated perspective, intercept means and variances were constrained to be equal on the one measurement occasion of overlap between the two age cohorts (i.e., T5 for early to middle adolescents, and $\mathrm{T} 1$ for middle to late adolescents. Growth of reconsideration was characterized by a curvilinear pattern, and is therefore a combination of linear and a quadratic slope

$* p<.05, * * p<.01, * * * p<.001$

standard deviations of commitment, in-depth exploration, and reconsideration for early to middle and middle to late adolescent boys and girls, are presented in Table 1.

The final model, including growth curves of commitment, in-depth exploration, and reconsideration, and associations between these dimensions, had a good fit $\left(\chi^{2}(302)=\right.$ 539.72, $p<.001$; CFI $=.97$; TLI $=.96$; $\mathrm{RMSEA}=.05)$. Estimated means of intercepts and slopes are displayed in Table 2. Since especially the curvilinear pattern of reconsideration (which is a combination of a linear and quadratic slope) is hard to judge from a table, growth curves of commitment, in-depth exploration, and reconsideration are also plotted for boys (Fig. 1a) and girls (Fig. 1b).

Levels of commitment were stable throughout the entire adolescent period. For early to middle and middle to late adolescent boys and girls, slopes of commitment never reached significance. There were no gender differences in intercepts of commitment.

For in-depth exploration, our hypothesis was confirmed as increases were found. Levels of in-depth exploration were stable in early to middle adolescent boys and girls, but increased significantly in a linear fashion for middle to late adolescent boys and girls. Chi-square difference tests revealed that girls displayed higher levels of in-depth exploration when compared to boys throughout the entire period of adolescence. Boys and girls exhibited similar change rates.

Development of reconsideration was characterized by a curvilinear pattern that was different for early to middle adolescent boys and girls, and middle to late adolescent boys and girls (chi-square difference test: $p<.05$ ). In early to middle adolescence, girls displayed lower levels of 


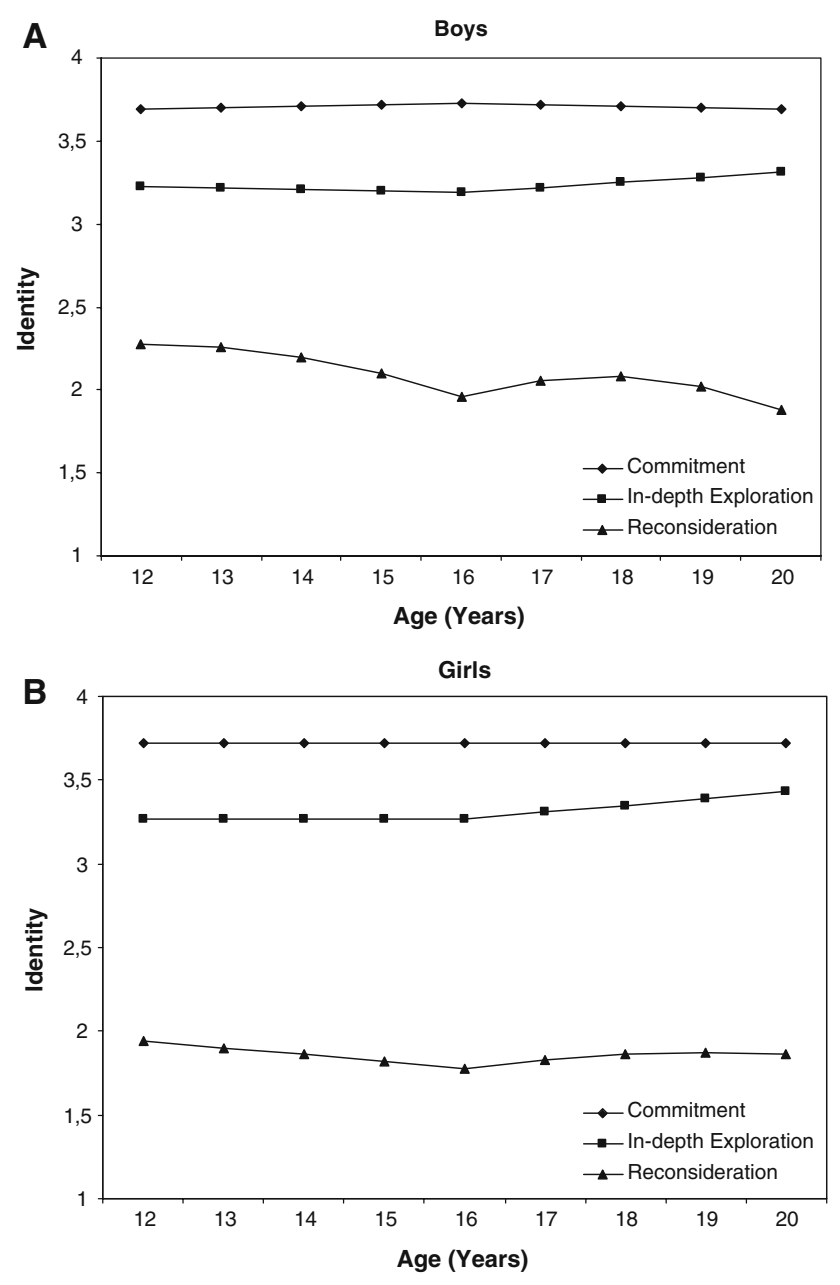

Fig. 1 Estimated growth of commitment, in-depth exploration, and reconsideration in boys (a) and girls (b)

reconsideration than boys. However, because boys exhibited significant curvilinear decreases in reconsideration whereas girls did not change significantly, the initial differences between boys and girls became smaller towards middle adolescence. In middle adolescence, gender differences initially became larger as girls did not change significantly, whereas boys increased in reconsideration.
However, the increase for boys in middle adolescence was followed by a sharp decrease in late adolescence. Since girls' levels of reconsideration remained stable from middle to late adolescence, gender differences in reconsideration became much smaller in late adolescence.

\section{Rank-Order Stability of Identity Dimensions}

Pearson correlations were calculated to assess the test-retest rank-order stability of identity dimensions (commitment, in-depth exploration, and reconsideration) across the five annual waves of this study, for boys and girls separately (see Table 3). We tested for significance of differences in rank-order stability between the four groups distinguished in the current study (i.e., early to middle and middle to late adolescent boys and girls). For that purpose, correlation coefficients were first transformed to $z$-scores using Fisher's $r$-to- $z$ transformation, and these $z$-scores were compared.

These analyses revealed that test-retest correlations of identity in early to middle adolescence did not significantly differ from test-retest correlations in middle to late adolescence, for both boys and girls. We did find gender differences in rank-order stability in early to middle adolescence, as rank-order stability was significantly higher for boys than for girls for commitment $(r=.38$ and $r=.26$, for boys and girls, respectively) and reconsideration $(r=.39$ and $r=.26$, for boys and girls, respectively).

\section{Profile Similarity in Identity Formation}

Profile similarity was measured by calculating $q$-correlations (e.g., Roberts et al. 2001) over the four-year period of this study for early to middle and middle to late adolescent boys and girls (see Table 3 ). Average $q$-correlations were high, demonstrating high profile similarity in early to middle and the middle to late adolescent boys and girls. Furthermore, we found a gender by age cohort interaction in increases of $q$-correlations. More specifically, boys had significantly lower levels of profile similarity in early to

Table 3 Rank-order stability and profile similarity of identity dimensions

\begin{tabular}{|c|c|c|c|c|}
\hline & \multicolumn{2}{|l|}{ Boys } & \multicolumn{2}{|l|}{ Girls } \\
\hline & $\begin{array}{l}\text { Early to middle } \\
\text { adolescence }\end{array}$ & $\begin{array}{l}\text { Middle to late } \\
\text { adolescence }\end{array}$ & $\begin{array}{l}\text { Early to middle } \\
\text { adolescence }\end{array}$ & $\begin{array}{l}\text { Middle to late } \\
\text { adolescence }\end{array}$ \\
\hline Commitment & $.38 * * *, \mathrm{a}$ & $.39 * * *, \mathrm{a}, \mathrm{b}$ & $.26 * * *, \mathrm{~b}$ & $.31 * * *, \mathrm{a}, \mathrm{b}$ \\
\hline In-depth exploration & $.37 * * *, \mathrm{a}$ & $.38 * * *, \mathrm{a}$ & $.27 * * *, \mathrm{a}$ & $.29 * * *, \mathrm{a}$ \\
\hline Reconsideration & $.39 * * *, \mathrm{a}$ & $.24 * *, \mathrm{a}, \mathrm{b}$ & $.26 * * *, \mathrm{~b}$ & $.34 * * *, a, b$ \\
\hline Profile Similarity & $.73^{\mathrm{a}}$ & $.83^{\mathrm{b}}$ & $.82^{\mathrm{b}}$ & $.85^{\mathrm{b}}$ \\
\hline
\end{tabular}

Note: Different superscripts within a line represent significant differences between groups $(p<.05)$

$* p<.05, * * p<.01, * * * p<.001$ 
middle adolescence when compared to girls $[t(853.210)=-2.858, p=.004, d=-.201]$. Since boys' levels of profile similarity increased in middle to late adolescence $[t(401.594)=-2.645, p=.008, d=-.227]$ whereas girls exhibited no further increases, gender differences in profile similarity were no longer present in middle to late adolescence.

\section{Discussion}

Erikson (1972, 1974) described the formation of an unambiguous identity as the central developmental task of adolescence. The main purpose of the current study was to provide a comprehensive view on identity formation in adolescence by examining three types of change and stability, using a five-annual-wave longitudinal design. A three-dimension model of identity formation (Crocetti et al. 2008b) was employed. In general, our findings were consistent with previous studies (e.g., Luyckx et al. 2008, 2006a; Meeus et al. 1999; Van Hoof 1999; Waterman 1999), as we found evidence for stability but also for small progressive developmental changes as adolescents grew older. These findings applied to both boys and girls.

\section{Stability and Change in Identity Formation}

Through Adolescence

Levels of commitment remained stable throughout the entire period of adolescence, for both boys and girls. Previous studies either found small increases (Meeus et al. 1999) or small decreases (Luyckx et al. 2006a, 2008). Thus, if previous studies and the present study are taken together, the best conclusion with regard to commitment is that there appear to be no meaningful changes across time. As rank-order stability of commitment was quite high in both early to middle and middle to late adolescent boys and girls, this mean-level stability should be interpreted as a normative trend (e.g., Roberts and DelVecchio 2000) that applied to a vast majority of adolescents. Thus, results for commitment provide support for Van Hoof's (1999) concept of stability in identity formation. With regard to gender differences in commitment, we found that rankorder stability of boys was higher than for girls in early to middle adolescence. Further gender differences were not found for commitment.

Additionally, our results demonstrated that adolescents' current commitments were increasingly more explored as they grew older, as we found increases for in-depth exploration in middle to late adolescent boys and girls. Similar findings have been obtained in previous studies (Luyckx et al. 2006a, 2008). Mean levels of in-depth exploration were stable in early to middle adolescent boys and girls. Similar to our results concerning commitment, rank-order stability did not increase with age in adolescence. No gender differences in rank-order stability of indepth exploration were found, but mean-levels of in-depth exploration were somewhat higher for girls than for boys throughout adolescence. In-depth exploration involves reflection on one's current commitments. Since girls have been shown to exhibit higher levels of self-reflection in general (Burwell and Shirk 2007), it is perhaps not too surprising that they exhibit higher levels of reflection on current commitments. Levels of rank-order stability for indepth exploration were quite high, which indicates that mean-level changes applied to a majority of individuals. Thus, middle to late adolescence is a period where most boys and girls start to explore their commitments in an increasingly active manner.

For reconsideration, we found profound gender differences. Throughout adolescence, girls displayed lower levels of reconsideration when compared to boys. These gender differences can be explained from an evolutionary point-of-view. Compared to boys, girls have a stronger preference to hold on to existing social bonds (Geary et al. 2003). High levels of reconsideration in the interpersonal domain would threaten social bonds directly, and reconsideration in the educational domain would threaten these bonds indirectly since much of an adolescents' social network is embedded in their school. As such, high levels of reconsideration could be particularly maladaptive for girls and less so for boys. This could be the reason why girls exhibit lower levels of reconsideration when compared to boys.

Besides gender differences in levels of reconsideration, there were also gender differences in change rates. Boys exhibited mean-level decreases in early to middle adolescence, whereas girls did not exhibit any significant changes throughout adolescence. Boys' decreases were only small in early adolescence, but became increasingly larger towards middle adolescence. These findings suggest that early to middle adolescence is a period where boys become increasingly more certain about their commitments. In middle to late adolescence, boys first display a small increase in reconsideration, but this increase is followed by a decrease. Despite this temporary increase for boys, their mean levels of reconsideration in middle to late adolescence remained below their mean levels in early adolescence. As there were no age-related changes in the relatively high levels of rank-order stability we found in early to middle adolescent boys and girls, the developmental patterns we found should be perceived as normative developmental trends (e.g., Roberts and DelVecchio 2000). The normativity of the slight, temporary, increase in reconsideration for boys is underscored by the fact that it coincides with a normative transition, as adolescents 
advance from high school to university when they are approximately 16-18 years old. They end up in a new school environment and meet new people. Their friends might go to a different university, which is likely to affect friendships. As a result, adolescents might need to reevaluate their commitments to their old friends, and look for new ones. Entering a new form of education is also likely to affect the educational identity domain. Adolescents need to find out what their new education means for them. Hence, they need to explore and find out whether their choice for a certain major as well as a certain university suites their needs. For this purpose, they might need to compare their current education with several possible alternatives. Thus, if the developmental context of 16-18 years old Dutch adolescents is taken into account, an increase in reconsideration should not necessarily be considered maladaptive. Our findings therefore underscore the importance of considering the context in which identity formation occurs (e.g., Bosma and Kunnen 2008). These results further demonstrate that our reconsideration scale is sensitive to changes in identity formation during normative transitions (i.e., the transition from high school to university), and thereby underscore the validity and importance of this relatively new identity dimension. What is unclear, however, is why the temporary increase in reconsideration only occurs for boys, especially since a previous study (Luyckx et al. 2008) demonstrated a similar curvilinear pattern for an identity dimension closely related to reconsideration (i.e., exploration in breadth) in a female college sample. It could be argued that the girls in the current study already possessed a more mature identity (indicated by higher levels of in-depth exploration and lower levels of reconsideration) by middle adolescence, when compared to boys. Girls' more mature identities should be indicative of a heightened sense of sameness and continuity across social contexts (Erikson 1972, 1974). As a result, they could perceive less of a need to adapt their identities in a new social context (i.e., university) and do not start to doubt their commitments when entering universities.

Across dimensions, levels of rank-order stability were quite high in both early to middle and middle to late adolescence. These findings indicate that individual differences in identity dimensions are already set to a large extent in early to middle adolescence, and do not become more set as adolescents grow older. We did find some gender differences in early to middle adolescence, as boys exhibited significantly higher levels of rank-order stability for commitment and reconsideration, when compared to girls. All the same, our results with regard to the three separate identity dimensions indicate that identity formation is characterized by stable individual differences across dimensions and stable mean levels of commitment, but with progressive mean-level changes for in-depth exploration in both boys and girls, and in reconsideration for boys. Thus, the current study indicates that identity commitments are increasingly better explored by both boys and girls (indicated by increases for in-depth exploration), while certainty about commitments is already high for girls in early adolescence, and increases for boys throughout adolescence (indicated by decreases in reconsideration). Taken together, our findings are not necessarily indicative of identity status changes, but they do suggest that adolescents move towards an achieved identity status. Therefore, our results support Waterman's $(1982,1999)$ concept of progressive change. Although the consistent overall pattern indicating progressive changes suggests that the changes we found are much more than just fluctuations in identity formation, the average change rate for the various identity dimensions was still rather small. As such, van Hoof's (1999) concept of stability also receives some support in the current study.

We found that profiles including all three identity dimensions distinguished in the current study (i.e., commitment, in-depth exploration, and reconsideration) were already quite stable for early to middle adolescent girls and did not become more stable for them in middle to late adolescence. Boys, on the other hand, had a less stable identity profile than girls in early to middle adolescence, but since their identity profile became much more stable in middle to late adolescence, they caught up with girls again. We found a similar pattern with regard to mean-level changes in reconsideration (i.e., boys initially had higher levels of reconsideration than girls, but displayed stronger decreases). Thus, similar to previous studies (Kroger 1997; Meeus et al. 1999; Waterman 1982, 1993, 1999), we found rather small overall gender differences in identity formation. However, there are gender differences in the timing of change. More specifically, girls seem to be ahead on boys in identity formation in early to middle adolescence, with boys catching up again in middle to late adolescence. Thus, girls seem to mature earlier with regard to identity formation than boys. Evidence for similar gender differences in the timing of developmental changes have not only been previously reported for identity formation (Kroger 1997), but also in the field of adolescent personality research (Klimstra in press). Gender differences in timing of maturation on psychological variables could be caused by similar gender differences in biological maturation, as girls are typically ahead on boys in pubertal timing (e.g., Petersen et al. 1988) and neurological development (Giedd et al. 1999). Future studies could investigate whether biological processes are indeed the cause of gender differences in the timing of adolescent identity formation.

Taken together, our findings reflect progressive changes in identity formation that apply to a majority of adolescents (as evidenced by relatively high levels of rank-order stability). The fact that the changes we found 
occurred in the relatively new identity dimensions in-depth exploration and reconsideration fits into our conceptualization of identity formation in adolescence. We propose that identity formation in adolescence is not specifically characterized by longitudinal increases in commitments themselves, but by increasing reflection on and certainty about commitments.

When taken as a whole, our results contribute to the debate on the timing of identity formation. Our results indicate that changes in identity formation take place both in early to middle adolescence, as predicted by Meeus (1996), and in middle to late adolescence as predicted by Marcia (1980) and Waterman (1982, 1993). Thus, the amount of change is not different in early to middle adolescence and middle to late adolescence, but differences between identity formation in early to middle adolescence and middle to late adolescence are related to specific dimensions. Findings for reconsideration suggested that early to middle adolescence is characterized by small increases in certainty about commitment for boys, but findings for in-depth exploration clearly indicated that middle to late adolescence is the period where commitments become more actively explored, for both boys and girls. Therefore, our results fit within the dual-cycle model proposed by Luyckx et al. (2006a). In their model, the first cycle, referred to as "the commitment formation cycle", represents the formation of stable commitments. We found some evidence for such a process in our data, reflected by mean-level decreases in reconsideration in early to middle adolescent boys. The second cycle, "the commitment evaluation cycle", involves actively thinking and evaluating present commitments. Evidence for this cycle is clearly represented in our data by increasing mean levels of in-depth exploration in middle to late adolescent boys and girls.

Some limitations of the current study should be noted. In this study, we focused on long-term changes. Identity formation is assumed to be characterized by inner conflicts or crises (Erikson 1972, 1974) that are hard to detect in studies with one-year intervals between measurements. In addition, the three-dimension model employed in the current study offers a dynamic conceptualization of identity formation (Crocetti et al. 2008b). However, with large intervals between measurement occasions the exact dynamics of identity development cannot be captured adequately (Luyckx et al. 2006a; Lichtwarck-Aschoff et al. 2008). To obtain a detailed perspective on the dynamics of identity formation, future studies should include more frequent measurements.

In this study of growth and stability in identity formation, our focus was on change in three identity dimensions. To disentangle the causes of inter-individual differences in identity formation, future studies should also address long-term associations of identity dimensions or statuses with other factors that have been shown to be related in cross-sectional studies, or should be theoretically related. For example, Luyckx et al. (2006c) already found strong evidence for a longitudinal interplay between personality and identity, but merely assessed late adolescent women. In another longitudinal study, Kroger and Haslett (1988) demonstrated that identity formation predicted attachment style. However, they only employed a small sample. Further research revealed cross-sectional links between identity dimensions on the one hand, and psychosocial problems (Crocetti et al. 2008b) and the separation-individuation process (Meeus et al. 2005) on the other hand. Taken together, the longitudinal associations between identity formation and factors like personality, separationindividuation (e.g., attachment), and psychosocial problems are not well-established. Future studies should aim to examine the relations between identity formation and these factors more thoroughly.

The current study also showed the importance of considering gender in identity formation, as girls exhibited more stability and maturity at the early stages of identity formation with boys catching up in late adolescence. Our findings regarding temporary increases in reconsideration for boys during the transition from high school to university already showed that it is also important to consider the developmental context in which identity formation occurs (Bosma and Kunnen 2008). Since these temporary increases in reconsideration only occurred for boys, our findings reveal that not only the main-effects of gender and context exert an influence on identity formation. In line with Kroger's recommendations (Kroger 1997), our results point towards the importance of studying the effect of gender by context interactions. Thus, future studies should assess the effects of gender, contextual factors, and the interactions of gender by context on identity formation whenever it is feasible.

In conclusion, the current study reveals that identity formation is described by both stability and progressive changes. No age-related changes were found with regard to rank-order stability of identity dimensions and mean levels of commitment. There was, however, evidence for progressive change, especially for boys. Boys gained an increasingly more stable identity profile (evidenced by increases in profile similarity), displayed a decreasing tendency for reconsideration throughout adolescence, and revealed increases in in-depth exploration in middle to late adolescence. Girls also exhibited progressive changes, as they displayed strong increases for in-depth exploration. Taken together, our findings indicate that identity formation is characterized by progressive changes in dealing with commitments, rather than by changes in commitments themselves. Therefore, our findings demonstrate the merits 
of a three-dimension approach to identity formation, with an emphasis on the relatively new identity dimensions of in-depth exploration and reconsideration.

Open Access This article is distributed under the terms of the Creative Commons Attribution Noncommercial License which permits any noncommercial use, distribution, and reproduction in any medium, provided the original author(s) and source are credited.

\section{References}

Balistreri, E., Busch-Rossnagel, N. A., \& Geisinger, K. F. (1995). Development and preliminary validation of the ego identity process questionnaire. Journal of Adolescence, 18, 179-192. doi: 10.1006/jado.1995.1012.

Bennion, L. D., \& Adams, G. R. (1986). A revision of the extended version of the objective measure of ego identity status: An identity instrument for use with late adolescents. Journal of Adolescent Research, 1, 183-198. doi:10.1177/074355488612005.

Block, J. (1971). Lives through time. Berkeley, CA: Bancroft books.

Block, J., \& Robins, R. W. (1993). A longitudinal study of consistency and change in self-esteem from early adolescence to early adulthood. Child Development, 64, 909-923. doi:10.2307/113 1226.

Bollen, K. (1989). Structural equations with latent variables. New York: Wiley.

Bosma, H. A., \& Kunnen, E. S. (2008). Identity-in-context is not yet identity development-in-context. Journal of Adolescence, 31, 281-289. doi:10.1016/j.adolescence.2008.03.001.

Burwell, R. A., \& Shirk, S. R. (2007). Subtypes of rumination in adolescence: Associations between brooding, reflection, depressive symptoms, and coping. Journal of Clinical Child and Adolescent Psychology, 36, 56-65. doi:10.1207/s15374424jccp3601_6.

Cohen, J. (1988). Statistical power analysis for the behavioral sciences (2nd ed.). Hillsdale, New Jersey: Erlbaum.

Crocetti, E., Rubini, M., Luyckx, K., \& Meeus, W. (2008a). Identity formation in early and middle adolescents from various ethnic groups: From three dimensions to five statuses. Journal of Youth and Adolescence, 37, 983-996. doi:10.1007/s10964-007-9222-2.

Crocetti, E., Rubini, M., \& Meeus, W. H. J. (2008b). Capturing the dynamics of identity formation in various ethnic groups: Development and validation of a three-dimensional model. Journal of Adolescence, 31, 207-222. doi:10.1016/j.adolescence.2007.09.002.

De Fruyt, F., Bartels, M., Van Leeuwen, K. G., De Clercq, B., Decuyper, M., \& Mervielde, I. (2006). Five types of personality continuity in childhood and adolescence. Journal of Personality and Social Psychology, 91, 538-552. doi:10.1037/0022-3514.91. 3.538 .

Duncan, T. E., Duncan, S. C., Stryker, L. A., Li, F., \& Alpert, A. (1999). An introduction to latent variable growth curve modelling. Mahwah, NJ: Lawrence Erlbaum Associates, Inc.

Erikson, E. H. (1972). Childhood and society (Repr. ed. ed.). Harmondsworth, Middlesex: Penguin Books.

Erikson, E. H. (1974). Identity: Youth and crisis (Repr. ed. ed.). London: Faber and Faber.

Geary, D. C., Byrd-Craven, J., Hoard, M. K., Vigil, J., \& Numtee, C. (2003). Evolution and development of boys' social behavior. Developmental Review, 23, 444-470. doi:10.1016/j.dr.2003. 08.001.

Giedd, J. N., Blumenthal, J., Jeffries, N. O., Castellanos, F. X., Liu, H., Zijdenbos, A., et al. (1999). Brain development during childhood and adolescence: A longitudinal mri study. Nature Neuroscience, 2, 861-863. doi:10.1038/13158.
Hu, L., \& Bentler, P. M. (1999). Cutoff criteria for fit indexes in covariance structure analysis: Conventional criteria versus new alternatives. Structural Equation Modeling, 6, 1-55.

Klimstra, T. A., Hale, W. W., III, Raaijmakers, Q. A. W., Branje, S. J. T., Meeus, W. H. J. (in press). Maturation of personality in adolescence. Journal of Personality and Social Psychology.

Kline, R. B. (1998). Principles and practice of structural equation modeling. London: The Guilford Press.

Kroger, J. (1997). Gender and Identity: The intersection of Structure, Content, and Context. Sex Roles, 36, 747-770. doi:10.1023/A: 1025627206676.

Kroger, J. (2007). Presidential address: The status of identity. Paper presented at the 14th Annual Conference of the Society for Research on Identity Formation, George Washington University, Ashburn, Virginia.

Kroger, J., \& Haslett, S. J. (1988). Separation-individuation and ego identity status in late adolescence: A two-year longitudinal study. Journal of Youth and Adolescence, 17, 59-79. doi:10.1007/BF 01538724 .

Lichtwarck-Aschoff, A., van Geert, P. L. C., Bosma, H. A., \& Kunnen, E. S. (2008). Time and identity: A framework for research and theory formation. Developmental Review, 28, 370 400. doi:10.1016/j.dr.2008.04.001.

Little, R. (1988). A test of missing completely at random for multivariate data with missing values. Journal of the American Statistical Association, 83, 1198-1202. doi:10.2307/2290157.

Luyckx, K., Goossens, L., \& Soenens, B. (2006a). A developmental contextual perspective on identity construction in emerging adulthood: Change dynamics in commitment formation and commitment evaluation. Developmental Psychology, 42, 366380. doi:10.1037/0012-1649.42.2.366.

Luyckx, K., Goossens, L., Soenens, B., \& Beyers, W. (2006b). Unpacking commitment and exploration: Preliminary validation of an integrative model of late adolescent identity formation. Journal of Adolescence, 29, 361-378. doi:10.1016/j.adolescence. 2005.03.008.

Luyckx, K., Schwartz, S. J., Goossens, L., Soenens, B., \& Beyers, W. (2008). Developmental typologies of identity formation and adjustment in female emerging adults: A latent class growth analysis approach. Journal of Research on Adolescence, 18, 595-619. doi:10.1111/j.1532-7795.2008.00573.x.

Luyckx, K., Soenens, B., \& Goossens, L. (2006c). The personalityidentity interplay in emerging adult women: Convergent findings from complementary analyses. European Journal of Personality, 20, 195-215. doi:10.1002/per.579.

Marcia, J. E. (1966). Development and validation of ego-identity status. Journal of Personality and Social Psychology, 3, 551558. doi:10.1037/h0023281.

Marcia, J. E. (1980). Identity in adolescence. In J. Adelson (Ed.), Handbook of adolescent psychology. New York: Wiley.

Marcia, J. E. (2007). Theory and measure: The identity status interview. In M. Watzlawik \& A. Born (Eds.), Capturing identity: Quantitative and qualitative methods (pp. 1-14). Lanham, MD: University Press of America.

Matteson, D. R. (1977). Exploration and commitment: Sex differences and methodological problems in the use of identity status categories. Journal of Youth and Adolescence, 6, 353-374. doi: 10.1007/BF02139239.

Meeus, W. H. J. (1996). Studies on identity development in adolescence: An overview of research and some new data. Journal of Youth and Adolescence, 25, 569-598. doi:10.1007/BF 01537355 .

Meeus, W. H. J., Akse, J., Branje, S. J. T., Ter Bogt, T. F. M., Crommelin, P. M., Delsing, M. J. M. H., et al. (2006). Codebook of the research project conflict and management of relationships 
(conamore). Unpublished manuscript, Utrecht University, The Netherlands, 2006.

Meeus, W. H. J., Iedema, J., Helsen, M., \& Vollebergh, W. (1999). Patterns of adolescent identity development: Review of literature and longitudinal analysis. Developmental Review, 19, 419-461. doi:10.1006/drev.1999.0483.

Meeus, W. H. J., Iedema, J., Maassen, G., \& Engels, R. (2005). Separation-individuation revisited: On the interplay of parentadolescent relations, identity and emotional adjustment in adolescence. Journal of Adolescence, 28, 89-106. doi:10.1016/ j.adolescence.2004.07.003.

Muthén, L. K., \& Muthén, B. O. (2007). Mplus user's guide (4th ed.). Los Angeles, CA: Muthén \& Muthén.

Ozer, D. J., \& Gjerde, P. F. (1989). Patterns of personality consistency and change from childhood through adolescence. Journal of Personality, 57, 483-507. doi:10.1111/j.1467-6494.1989.tb00 490.x.

Petersen, A. C., Crockett, L., Richards, M., \& Boxer, A. (1988). A self-report measure of pubertal status-reliability, validity, and initial norms. Journal of Youth and Adolescence, 17, 117-133. doi:10.1007/BF01537962.

Roberts, B. W., Caspi, A., \& Moffitt, T. E. (2001). The kids are alright: Growth and stability in personality development from adolescence to adulthood. Journal of Personality and Social Psychology, 81, 670-683. doi:10.1037/0022-3514.81.4.670.

Roberts, B. W., \& DelVecchio, W. F. (2000). The rank-order consistency of personality traits from childhood to old age: A quantitative review of longitudinal studies. Psychological Bulletin, 126, 3-25. doi:10.1037/0033-2909.126.1.3.

Robins, R. W., Fraley, R. C., Roberts, B. W., \& Trzesniewski, K. H. (2001). A longitudinal study of personality change in young adulthood. Journal of Personality, 69, 617-640. doi:10.1111/ 1467-6494.694157.

Satorra, A., \& Bentler, P. M. (1994). Corrections to test statistics and standard errors in covariance structure analysis. In A. Von Eye \& C. C. Clogg (Eds.), Latent variables analysis: Applications for developmental research (pp. 399-419). Thousand Oaks, CA: Sage Publications.

Satorra, A., \& Bentler, P. M. (2001). A scaled difference chi-square test statistic for moment structure analysis. Psychometrika, 66, 507-514. doi:10.1007/BF02296192.

Statistics Netherlands. (2003). Jeugd 2003, cijfers en feiten [Dutch youth 2003, numbers and facts]. Voorburg, The Netherlands: Statistics Netherlands.

van Hoof, A. (1999). The identity status field re-reviewed: An update of unresolved and neglected issues with a view on some alternative approaches. Developmental Review, 19, 497-556. doi:10.1006/drev.1999.0484.
Waterman, A. S. (1982). Identity development from adolescence to adulthood: An extension of theory and a review of research. Developmental Psychology, 18, 342-358. doi:10.1037/00121649.18.3.341.

Waterman, A. S. (1993). Developmental perspectives on identity formation: From adolescence to adulthood. In J. E. Marcia, A. S. Waterman, D. R. Matteson, S. Archer, \& J. L. Orlofsky (Eds.), Ego identity. New York: Springer Verlag.

Waterman, A. S. (1999). Identity, the identity statuses, and identity status development: A contemporary statement. Developmental Review, 19, 591-621. doi:10.1006/drev.1999.0493.

\section{Author Biographies}

Theo A. Klimstra is a doctoral student at the Research Centre Adolescent Development of Utrecht University. His research interests include identity formation and personality development in adolescence.

William W. Hale III is Assistant Professor at the Research Centre Adolescent Development, Utrecht University. He received his Ph.D. at the Department of Biological Psychiatry, University of Groningen. His major research interests include adolescent depression and anxiety, and the effects parental interactions have on these psychosocial problem behaviors.

Quinten A. W. Raaijmakers is an Associate Professor at the Research Centre Adolescent Development, Utrecht University. He received his Ph.D. in Psychology from the same university. His major research interests include socio-moral identity development in adolescents, adolescent adjustment and methods and statistics.

Susan J. T. Branje is an Associate Professor at the Research Centre Adolescent Development, Utrecht University. She received her Ph.D. in 2003 from the Radboud University Nijmegen. Her research interests include adolescent development and the influence of parents and friends.

Wim H. J. Meeus is Professor of Adolescent Development and chair of the Research Centre Adolescent Development of Utrecht University. He received his Ph.D. in Social Psychology from the same university. His major research interests include personality, identity, and relationships in adolescence. 